\title{
Activation of Resistance Arteries with Endothelin-1: From Vasoconstriction to Functional Adaptation and Remodeling
}

\author{
Erik N.T.P. Bakker ${ }^{a}, b \quad$ Carsten L. Buus ${ }^{a}$ Ed VanBavel ${ }^{b}$ Michael J. Mulvany ${ }^{a}$ \\ a Department of Pharmacology, University of Aarhus, Aarhus, Denmark; b Department of Medical Physics, \\ Academic Medical Center and Cardiovascular Research Institute Amsterdam, Amsterdam, The Netherlands
}

\section{Key Words}

Collagen · Endothelin-1 - Integrins · Microcirculation • Organ culture $\cdot$ Resistance arteries $\cdot$ Vasoconstriction

\begin{abstract}
Remodeling of resistance arteries is a key feature in hypertension. We studied the transition of vasoconstriction to remodeling in isolated rat skeletal muscle arterioles. Arterioles activated with $10 \mathrm{n} M$ endothelin-1 showed functional adaptation when kept at low distension in a wire myograph setup, where contractile properties shifted towards a smaller lumen diameter after 1 day. Pressurized arteries kept in organoid culture showed physical inward remodeling after 3-day activation with $10 \mathrm{n} M$ endothelin-1, characterized by a reduction in relaxed diameter without a change in the wall cross-sectional area (eutrophic remodeling). The relaxed lumen diameter (at $60 \mathrm{~mm} \mathrm{Hg}$ ) decreased from $169 \pm 5$ (day 0 ) to $155 \pm 4 \mu \mathrm{m}$ (day 3). An antibody directed to the $\beta_{3}$-integrin subunit (but not one directed to the $\beta_{1}$-integrin subunit) enhanced remodeling, from a reduction in relaxed diameter at $60 \mathrm{~mm} \mathrm{Hg}$ of $15 \pm 2.4$ to $22 \pm 1.8 \mu \mathrm{m}$ (both on day 3). Collagen gel contraction experiments showed that the antibody directed to the $\beta_{3}$-integrin subunit enhanced the compaction of collagen by smooth
\end{abstract}

muscle cells, from $83 \pm 1.5$ to $68 \pm 1.5 \%$ of the initial gel diameter. In conclusion, these data show that inward eutrophic remodeling is a response to sustained contraction, which may involve collagen reorganization through $\beta_{3}$-integrins.

Copyright $\odot 2004$ S. Karger AG, Basel

\section{Introduction}

Hypertension is associated with a structurally determined increase in the wall-to-lumen ratio of the vasculature. In the conduit arteries, this remodeling is characterized by either no change or an increase in the lumen diameter, the increased wall-to-lumen ratio thus being due to hypertrophy, an increase in wall material. In the resistance arteries, the lumen diameter is decreased, and the amount of wall material is either increased (hypertrophy) or unchanged, being due to a rearrangement of the wall material around the smaller lumen (eutrophy), depending on the type or model of hypertension [1]. Thus the rat angiotensin-II infusion model $[2,3]$ of hypertension results in hypertrophic remodeling of the small arteries, a finding which has also been reported for the spontaneously hypertensive rat [4], although in that model the results are variable. In human renovascular hypertension, hyper-

\begin{tabular}{ll}
\hline KARGER & ( 2004 S. Karger AG, Basel \\
1018-1172/04/0412-0174\$21.00/0 \\
$\begin{array}{l}\text { Fax +4161306 12 34 } \\
\begin{array}{l}\text { E-Mail karger@karger.ch } \\
\text { www.karger.com }\end{array}\end{array}$ & $\begin{array}{l}\text { Accessible online at: } \\
\text { www.karger.com/jvr }\end{array}$
\end{tabular}

Dr. Erik N.T.P. Bakker

Department of Medical Physics, Academic Medical Center

PO Box 22700

NL-1100 DE Amsterdam (The Netherlands)

Tel. +3120 5665179, Fax +31206917233, E-Mail n.t.bakker@amc.uva.nl 
trophic remodeling of small arteries has been reported [5], but in essential hypertension, the form of remodeling appears to be eutrophic [6-10]. An understanding of the mechanisms involved in eutrophic remodeling is therefore needed if the vascular changes seen in essential hypertension are to be clarified.

Until recently, mainly in vivo models have been used for studying the altered structure of small arteries in hypertension. However, recently a number of groups have used isolated vessels, cannulated and held under pressure for various periods of time. This has enabled the investigation of the effects of pressure and mitogens on mechanisms (e.g. extracellular signal-related kinase, ERK1/2) known from cell culture experiments to be involved in growth processes [11-13]. Such experiments may be expected to be of relevance to situations involving hypertrophic remodeling, although the experiments so far reported have not been long enough to detect changes in wall material. Other experiments by some of us have involved organ culture $[14,15]$. These experiments have shown that when cultured for 3 days under pressure and during continuous activation either by fetal calf serum or by endothelin-1, physical remodeling can be detected; that is, when examined under relaxed conditions and a given pressure, the diameter of the vessel is reduced following the culture. Moreover, this physical remodeling is not associated with an increase in wall material: it is due to eutrophic remodeling. Thus an in vitro model has now been developed which can mimic the type of remodeling which is seen in human essential hypertension.

The aim of the present study was to delineate the transition of vasoconstriction to physical remodeling. The questions which have been addressed are: (1) which signal transduction pathways are involved in remodeling; (2) how is activation linked to rearrangement of the extracellular matrix, and (3) does activation result in functional adaptation, i.e. changes in the contractile properties, prior to physical remodeling. Physical remodeling was studied using isolated vessels in organoid culture, and the interaction of smooth muscle cells with the extracellular matrix was further explored using a collagen contraction assay. The possibilities of the wire myograph setup were exploited to study functional adaptation. In most cases, endothelin-1 was used to induce activation, and the effects of inhibitors of ERK1/2 activation and tyrosine kinase were used to study possible signal transduction pathways. Antibodies against $\beta_{1}$ - and $\beta_{3}$-integrin subunits were used to study possible mechanisms of the transmission of cell signals to the extracellular matrix.

Endothelin-1: Functional Adaptation and

Remodeling

\section{Methods}

In accordance with institutional guidelines, male Wistar rats (Møllegaard, Denmark), 10-12 weeks of age, were stunned by a blow on the head and decapitated. Cremaster muscles were excised under sterile conditions and placed in cold, sterile Krebs-Henseleit buffer (Sigma), pH 7.35. Segments of the first-order arteriole of 2-4 mm length were dissected from the muscle and used in an organ culture setup (Danish Myo Technology) or a wire myograph setup (Danish Myo Technology).

\section{Wire Myograph}

The bath of the wire myograph setup was filled with physiological saline solution of the following composition (in $\mathrm{m} M$ ): $\mathrm{NaCl} 119$, $\mathrm{NaHCO}_{3} 25, \mathrm{KCl} 4.7, \mathrm{KH}_{2} \mathrm{PO}_{4} 1.18, \mathrm{MgSO}_{4} 1.17, \mathrm{CaCl}_{2} 2.5$, EDTA 0.027 and glucose 5.5. The solution was gassed with $5 \% \mathrm{CO}_{2} / 95 \%$ air, $\mathrm{pH}$ 7.4. Segments were mounted using $20-\mu \mathrm{m}$ wires and normalized according to a standard procedure [16] in the presence of papaverine to prevent active force development. A distension versus active tension relationship was established using 5-HT $\left(10^{-6} M\right)$. Active force induced by 5 -HT at each level of distension was calculated from the maximal force minus the passive force. Then, vessels were set at either $0.3 \mathrm{~L}_{100}$ (low distension) or $0.9 \mathrm{~L}_{100}$ (normal distension) and activated with $10^{-8} \mathrm{M}$ endothelin-1 overnight. After this period, endothelin- 1 was washed out for $1 \mathrm{~h}$ and a second distension versus active tension relationship was established.

\section{Organoid Culture}

Organoid culture was performed as described previously [14]. Briefly, vessels were tied to glass cannulas on both ends and pressurized to $75 \mathrm{~mm} \mathrm{Hg}$. The organ bath was mounted on top of a microscope, equipped with a digital camera that was connected to a computer. Diameter of the vessels was measured using Vediview software and recorded continuously. The vessels were equilibrated to $34^{\circ} \mathrm{C}$ and developed a spontaneous tone within $1 \mathrm{~h}$ after equilibration. Medium, agonists and inhibitors were substituted daily.

The first series of culture experiments was done using DMEM (Gibco), which was recirculated from a reservoir of $50 \mathrm{ml}$ that was gassed with $5 \% \mathrm{CO}_{2}$ and $95 \%$ air. Vessels were activated with $10^{-8} \mathrm{M}$ endothelin-1 for 3 days, with or without inhibitors, either genistein $\left(10^{-5} \mathrm{M}\right.$; Sigma) to inhibit tyrosine kinases or PD98059 $\left(10^{-5} \mathrm{M}\right.$; New England Laboratories) to block ERK1/2 activation. This concentration of genistein does not affect tone in these vessels [17]. PD98059 effectively blocks ERK1/2 activation at this concentration $[11,13]$. In a separate group, segments were stimulated with $35 \mathrm{mM}$ potassium medium, which comprised DMEM with additional potassium chloride.

In the second series of culture experiments, Leibovitz (Gibco) medium was used to reduce the amount of medium and inhibitors. This medium does not require $\mathrm{CO}_{2}$ to maintain $\mathrm{pH}$. The medium was not recirculated, thereby reducing the volume of medium to $\sim 1.5 \mathrm{ml}$. Monoclonal antibodies ( $\mathrm{mAb}$ ) directed against the $\beta_{1}$-integrin subunit (clone $\mathrm{Ha} 2 / 5$; hamster IgM, Pharmingen) and the $\beta_{3}$-integrin subunit (clone $\mathrm{F} 11$; mouse $\mathrm{IgG}_{1}$, Pharmingen) were used at a concentration of $50 \mu \mathrm{m} / \mathrm{ml}$. Both antibodies react with rat tissue.

In both series, contractile responses to 5 -HT $\left(10^{-7} M\right)$ were established on day 3 after washout of endothelin-1, potassium, and inhibitors. Passive pressure-diameter relationships were established at the start and end of the experimental protocol. For this purpose, vessels were incubated with $10^{-4} M$ papaverine on day 0 and incubated with 
$\mathrm{Ca}^{2+}$-free physiological saline solution containing $10^{-4} \mathrm{~mol} / \mathrm{l}$ papaverine on day 3. Pressure-diameter relationships were made after a 30-min incubation with the dilatory medium.

\section{Immunostaining}

Immunostaining for integrins containing the $\beta_{3}$-subunit was performed on sections of the cremaster muscle. Specimens were embedded in Tissue-tek medium and frozen in liquid nitrogen. Sections were fixed in cold acetone. Sections were incubated overnight at $4{ }^{\circ} \mathrm{C}$ with a dilution of 1:200 of the primary antibody (F11; Pharmingen). A kit for mouse antibody on rat tissue (DAKO) was used to detect the primary antibody and diaminobenzidine was used to reveal positive staining. Negative control sections were processed without the primary antibody.

\section{Collagen Gel Contraction}

Vascular smooth muscle cells were isolated from rat aorta using $4 \mathrm{mg} / \mathrm{ml}$ collagenase, $1 \mathrm{mg} / \mathrm{ml}$ soybean trypsin inhibitor and $0.4 \mathrm{mg} /$ $\mathrm{ml}$ elastase. After enzymatic digestion of the aorta at $37^{\circ} \mathrm{C}$ for $75 \mathrm{~min}$, cells were centrifuged and washed with Leibovitz medium. Cells were grown till confluence in culture flasks containing Leibovitz medium supplemented with $10 \%$ heat-inactivated FCS and antibiotics. For collagen gel contraction, cells were used at passage 3. Collagen gels were formed using rat tail collagen type I (Fluka). Collagen was dissolved in Leibovitz medium supplemented with $10 \%$ heatinactivated FCS, using $0.2 \mathrm{NHAc}$ at $4^{\circ} \mathrm{C}$. The $\mathrm{pH}$ of the solution was then adjusted to $\mathrm{pH} 7.4$ at room temperature. Collagen was allowed to polymerize in a 12 -well culture plate at $37^{\circ} \mathrm{C}$ for $1 \mathrm{~h}$, using $1 \mathrm{ml}$ of collagen solution per well. Cells were released from the culture flask with trypsin-EDTA (Gibco), counted, and $10^{5}$ cells were gently placed on top of each gel. Antibodies were added to the same concentration as in the organoid culture experiments and the gels were incubated at $37^{\circ} \mathrm{C}$ for 4 days.

\section{Statistics}

Data are expressed as means \pm SEM, with $n$ indicating the number of experiments. Mean data were compared by t test or ANOVA, followed by post-hoc analysis with Bonferroni correction or Dunnett's t test as appropriate. Data were considered significant when $\mathrm{p}<0.05$.

\section{Results}

\section{Functional Adaptation}

The wire myograph setup was used to study functional adaptation. Contraction was induced with 5-HT, which induced maximal tension within 3 min after addition of the agonist. Subsequent steps in distension revealed a typical lumen distension versus tension relationship (fig. 1). Segments that were activated overnight at $0.3 \mathrm{~L}_{100}$ showed a marked shift in contractile responses. Thus, contraction was enhanced at low distension, and impaired at high distension on day 1 as compared to day 0 (fig. 1a). The segments that were kept at $0.9 \mathrm{~L}_{100}$ did not show a change in the active tension-distension relationship (fig. 1b).
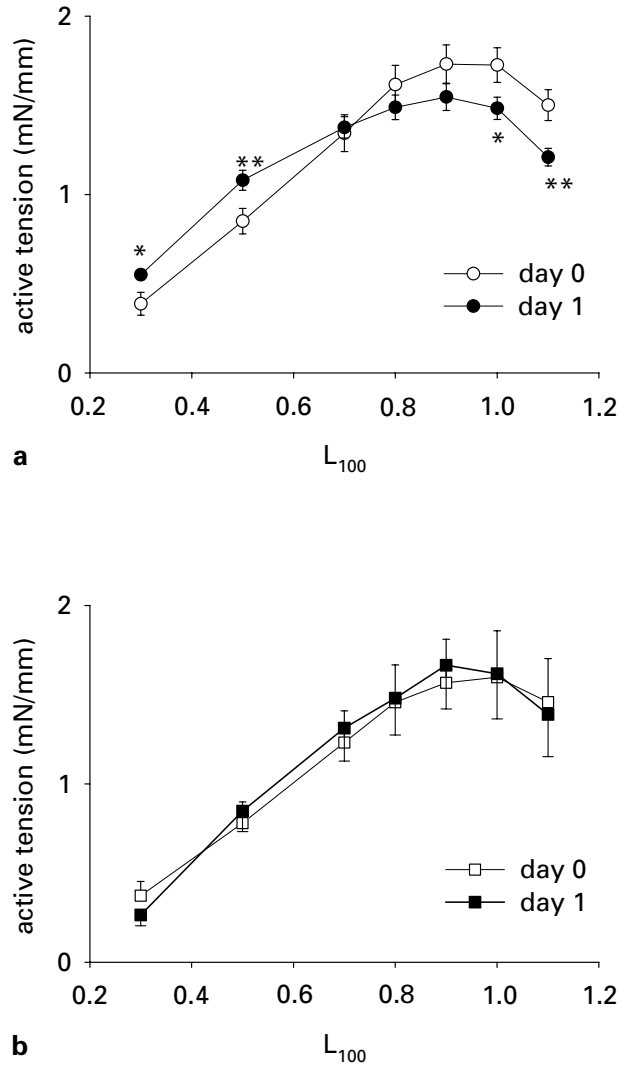

Fig. 1. Distension versus active tension relationship of cremaster muscle arterioles in a wire myograph setup. Active tension induced by $10^{-6} M 5$-HT was determined after successive steps in distension. Relationships were determined before and after a 1-day activation period with $10^{-8} M$ endothelin at $0.3 \mathrm{~L}_{100}(\mathbf{a} ; \mathrm{n}=6)$ and $0.9 \mathrm{~L}_{100}(\mathbf{b}$; $\mathrm{n}=6$ ). Vessels activated at low distension showed responses that were significantly increased at $0.3 \mathrm{~L}_{100}$ and $0.5 \mathrm{~L}_{100}$, and decreased at $1.0 \mathrm{~L}_{100}$ and $1.1 \mathrm{~L}_{100}$ as compared to day $0 . * \mathrm{p}<0.05,{ }^{* *} \mathrm{p}<0.01$.

\section{Physical Remodeling}

Physical remodeling was studied using the organ culture approach. In the first series of culture experiments, vessels were studied in DMEM. In this medium, segments developed spontaneous tone, resulting in a $\sim 30 \%$ reduction in inner diameter. Activation with endothelin-1 further enhanced vasoconstriction. While endothelin-1 was refreshed daily, some decrease in contractile response during the 3-day experimental period was noted. Addition of neither PD98059 nor genistein affected constriction induced by endothelin-1 (fig. 2). Stimulation with $35 \mathrm{~m} M$ potassium induced a remarkably stable level of 

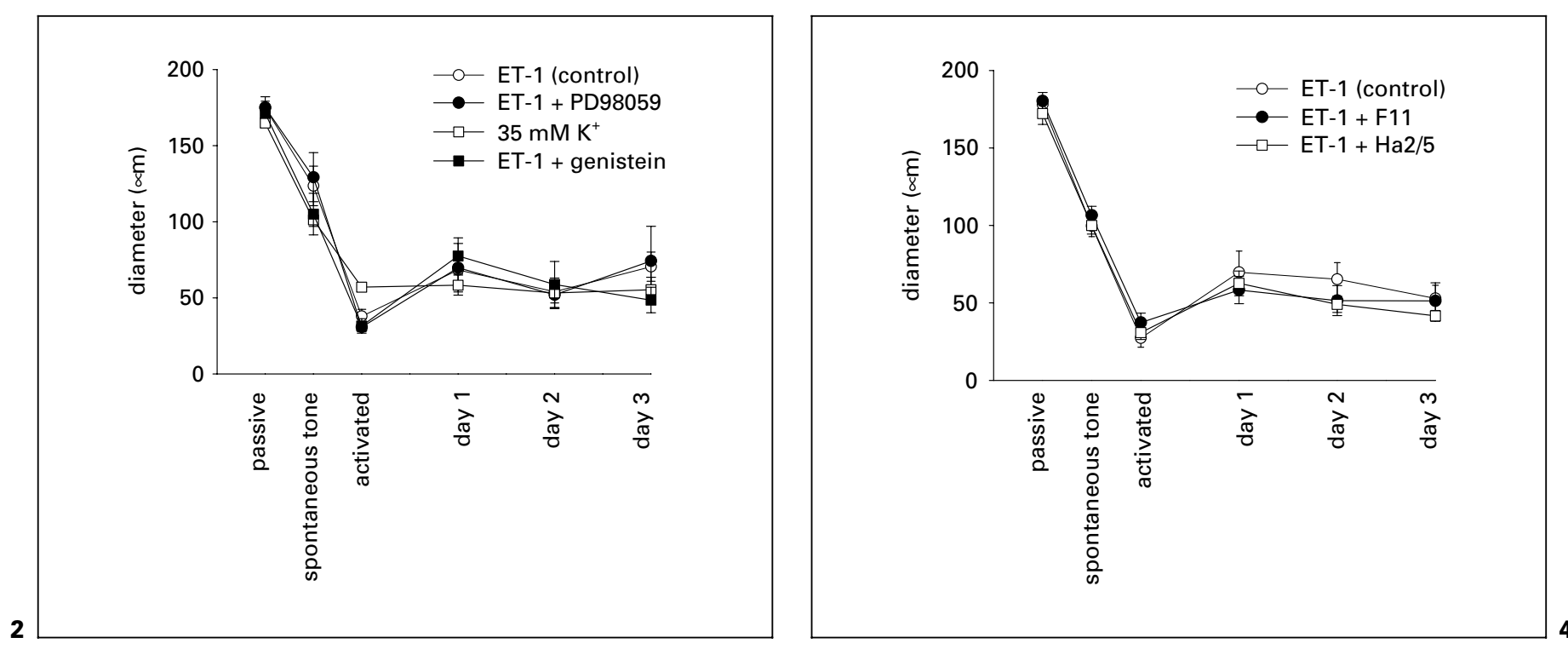

Fig. 2. Diameter of arterioles during organoid culture in DMEM. The maximal diameter at the start of the experiment was determined after incubation with $10^{-4} M$ papaverine. Arteriolar segments developed spontaneous tone after washout of papaverine, and were subsequently activated with $10^{-8} M$ endothelin- 1 or $35 \mathrm{mM}$ potassium $(\mathrm{n}=6)$ during a 3-day culture period. Arterioles were incubated with endothelin-1 only ( $\mathrm{n}=7$; control), or with endothelin-1 in combination with either $10^{-5} M$ PD98059 $(\mathrm{n}=4)$ or $10^{-5} M$ genistein $(\mathrm{n}=4)$. Endothelin-1 enhanced constriction throughout the culture period, as compared to spontaneous tone ( $\mathrm{p}<0.01$ for days $0-3$ vs. spontaneous tone).

Fig. 3. a Pressure vs. relaxed lumen diameter relation before (day 0 ) and after the culture period (day 3) in DMEM. Arterioles were activated during the culture period with $10^{-8} M$ endothelin-1 ( $\left.\mathrm{n}=7\right)$. $* \mathrm{p}<0.05, * * \mathrm{p}<0.01$ for day 0 vs. day 3 . b Inward remodeling, shown as reduction in relaxed lumen diameter at $60 \mathrm{~mm} \mathrm{Hg}$. Arterial segments were activated during organoid culture with endothelin-1 $(n=7)$, endothelin-1 in combination with PD98059 $(n=4)$, endothelin-1 in combination with genistein $(\mathrm{n}=4)$ or with $35 \mathrm{~m} M$ potassium in the absence of endothelin-1 $(n=6)$.

Fig. 4. Diameter of arterioles during organoid culture in Leibovitz medium. The maximal diameter at the start of the experiment was determined after incubation with $10^{-4} M$ papaverine. Arteriolar segments developed spontaneous tone after washout of papaverine, and were subsequently activated with $10^{-8} M$ endothelin-1. Segments were incubated with endothelin-1 only (control; $n=7$ ), or with endothelin- 1 and $\mathrm{mAb}$ directed against either the $\beta_{3}$-integrin subunit $(\mathrm{F} 11 ; \mathrm{n}=7)$ or with endothelin- 1 and $\mathrm{mAb}$ against the $\beta_{1}$-integrin subunit $(\mathrm{Ha} 2 / 5 ; \mathrm{n}=5)$. 

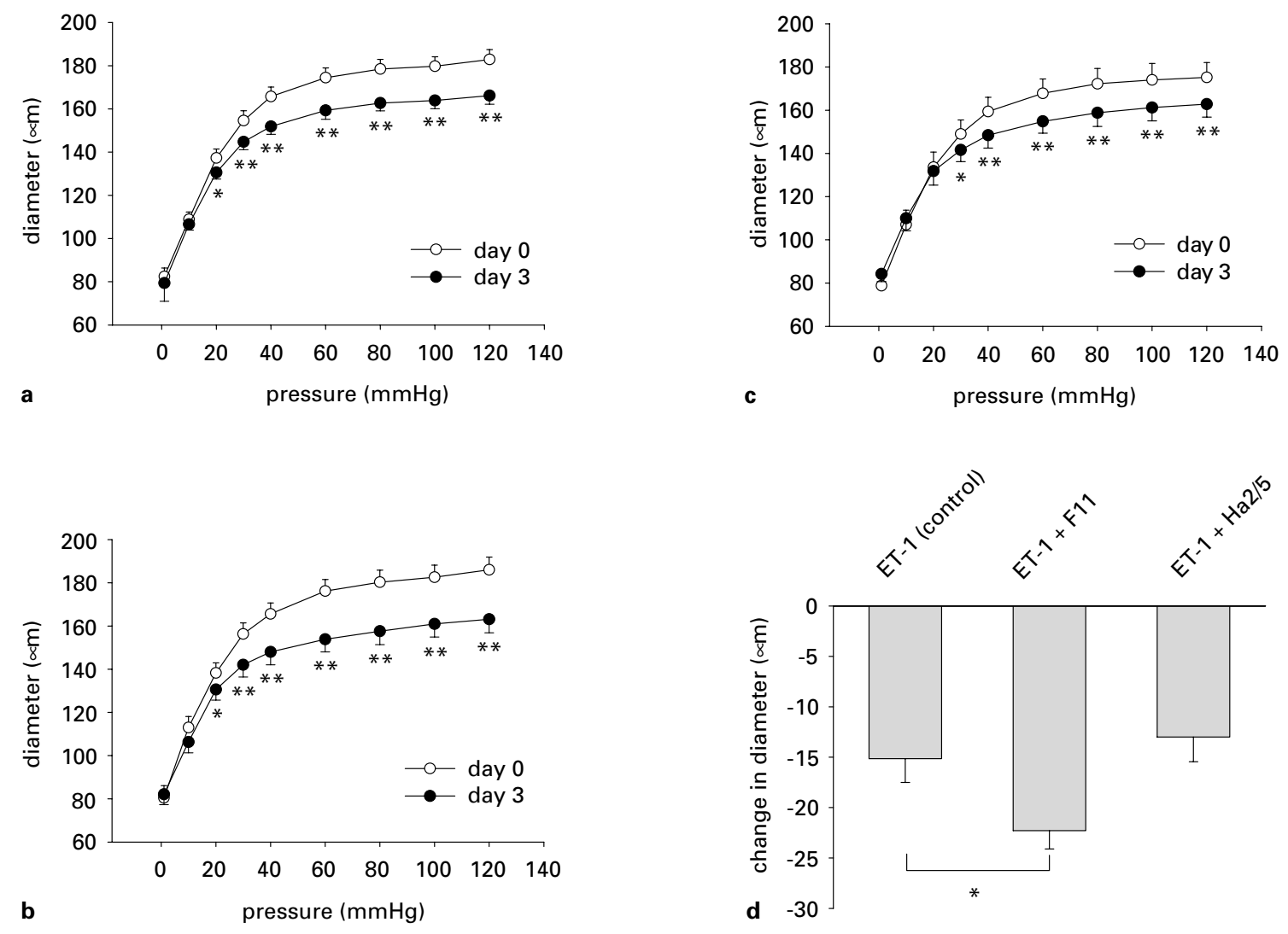

Fig. 5. a Pressure versus relaxed lumen diameter before (day 0 ) and after the culture period (day 3 ) in Leibovitz medium. Arterioles were activated during the culture period with endothelin-1 $(n=7)$. b Pressure versus relaxed lumen diameter of arterioles incubated with endothelin- 1 and $\mathrm{mAb} F 11$, directed against either the $\beta_{3}$-integrin subunit $(n=7)$. c Pressure versus relaxed lumen diameter of arteri- oles incubated with endothelin- 1 and the $\mathrm{mAb} \mathrm{Ha} 2 / 5$, directed against the $\beta_{1}$-integrin subunit $(\mathrm{n}=5)$. d Inward remodeling, shown as a reduction in relaxed lumen diameter at $60 \mathrm{~mm} \mathrm{Hg}$. Remodeling was significantly increased in segments treated with the $\mathrm{mAb}$ directed against the $\beta_{3}$-integrin subunit as compared to control. $* \mathrm{p}<0.05 ; * * \mathrm{p}<0.01$. tone throughout the experiment, to a level similar to that obtained with endothelin-1.

The passive pressure-diameter relationship showed a marked change after a 3-day activation period with endothelin-1. A significant decrease in diameter at higher pressure levels was found, when day 3 was compared to day 0 (fig. 3a). Segments that were incubated with PD98059 or genistein showed a similar pattern and extent of remodeling. Activation with $35 \mathrm{~m} M$ potassium mimicked the outcome of the experiments with endothelin-1 and resulted in a similar degree of remodeling (fig. 3b).

In the second series of culture experiments Leibovitz medium was used. In this medium, vessels developed a similar level of spontaneous tone and endothelin-1- induced constriction as compared to DMEM. Addition of antibodies against $\beta_{1}$ - or $\beta_{3}$-integrin subunits ( $\mathrm{Ha} 2 / 5$ and F11) did not alter vasoconstriction induced by endothelin-1 (fig. 4). However, inward remodeling of vessels incubated with the anti- $\beta_{3}$-antibody (F11) was enhanced as compared to endothelin-1 alone (fig. 5a, b). Incubation with the $\beta_{1}$-antibody induced a similar degree of remodeling as compared to endothelin-1 alone (fig. 5c). At $60 \mathrm{~mm}$ $\mathrm{Hg}$ (fig. 5d), the relaxed lumen diameter of arterioles incubated with a combination of endothelin-1 and mAb F11 showed a reduction in maximal diameter of $22 \pm 1.8$ vs. $15 \pm 2.4 \mu \mathrm{m}$ (F11 vs. control, $\mathrm{p}<0.05)$. To exclude any interference of differences in vessel size on day 0 , the reduction in passive diameter was also calculated as percentage. 


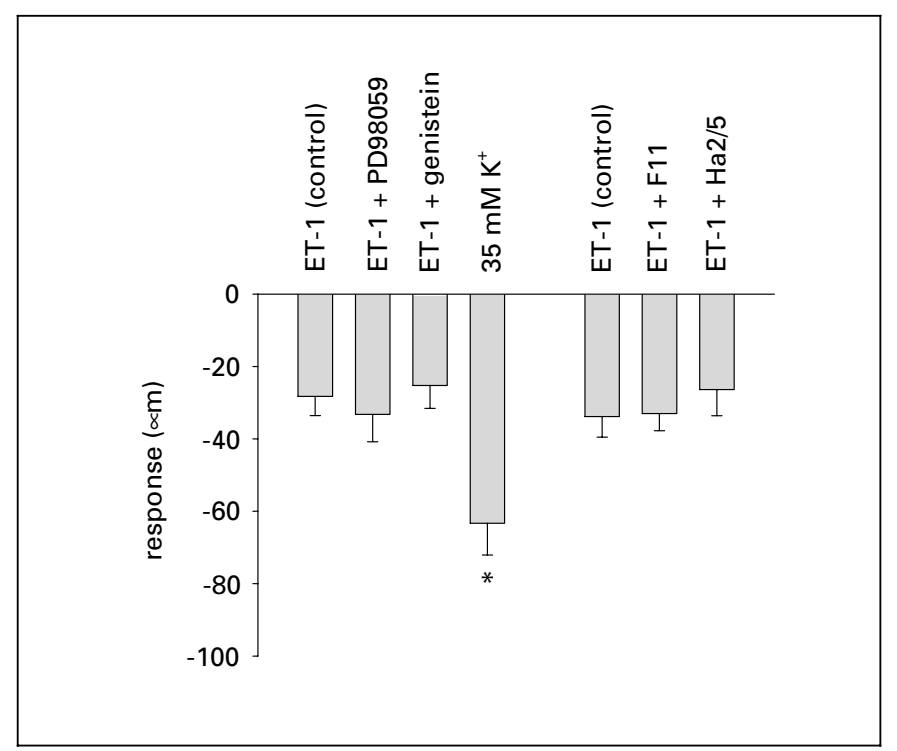

Fig. 6. Responses to $10^{-7} M 5$-HT, recorded on day 3 in DMEM (left 4 bars) and Leibovitz medium (right 3 bars). Responses were recorded during spontaneous tone, after washout of endothelin-1, inhibitors and $35 \mathrm{~m} M$ potassium. A significant increase in contractile response was observed in segments activated with potassium versus endothelin- $1 .{ }^{*} \mathrm{p}<0.01$.

This showed a similar result, with a reduction of $13 \pm 1.1$ vs. $8.6 \pm 1.2 \%$ (F11 vs. control, $\mathrm{p}<0.05$ ), indicating a $47 \%$ increase in remodeling with the antibody $\mathrm{F} 11$. The result of another approach to interfere with the $\alpha_{\mathrm{v}} \beta_{3}$-integrin, using a cyclic Arg-Gly-Asp (RGD) peptide (XJ735) at a concentration of $10^{-5} M$, was negative as neither remodeling nor vascular tone were affected (data not shown).

The wall cross-sectional area, as determined in vessels activated with endothelin- 1 in the absence of inhibitors and antibodies, did not change with remodeling: $8,636 \pm$ $720 \mu \mathrm{m}^{2}$ on day 0 vs. $8,275 \pm 652 \mu \mathrm{m}^{2}$ on day $3(\mathrm{n}=14)$. The reduction in the cross-sectional area was $5 \pm 7 \%$ on day 3 vs. day 0 .

On day 3 of the culture period, all segments constricted in response to 5-HT $\left(10^{-7} M\right)$. Contractile responses were similar in all groups after endothelin-1 activation, but enhanced in vessels after activation with potassium as compared to endothelin-1-actived vessels (fig. 6).

\section{Immunostaining}

Positive staining for the $\beta_{3}$-integrin subunit was found in the media of the arteriole (fig. 7a). Note that staining was absent in the first-order vein. Control sections where the primary antibody was absent were negative (fig. 7b).

\section{Collagen Gel Contraction}

Control gels were contracted to $83 \pm 1.5 \%$ of the initial diameter after 4 days. The antibody directed against the $\beta_{3}$-integrin subunit augmented contraction to $68 \pm$ $1.5 \%$ of the initial diameter, whereas the antibody directed to the $\beta_{1}$-integrin subunit completely inhibited collagen gel contraction (fig. 8).

\section{Discussion}

Both experimental and clinical evidence support an emerging concept of physical remodeling as a result of persistent functional responses. Thus, Langille et al. [18] showed that, after conduit artery ligation, inward remodeling followed persistent vasoconstriction, with similar results being obtained in rat mesenteric small arteries [19]. Using an in vitro approach, we provided direct evidence that active tone induces inward eutrophic remodeling of resistance arteries [15]. The possible clinical significance of the finding has been supported by analysis of the available literature on hypertensive treatment, which suggests that vasodilation, but not hypotension, is effective in the correction of vascular structure [20].

\section{Functional Adaptation}

We hypothesized that chronic activation would not only lead to rearrangement of the extracellular matrix, as evidenced by inward remodeling, but also of cellular elements. Such reorganization, which could involve the cytoskeleton or the active filaments, would be evidenced by changes in the contractile properties. We exploited the possibilities of the isometric wire myograph, to specifically test the role of distension in the response to endothelin- 1 . The distension was set at $0.3 \mathrm{~L}_{100}$, equivalent to the constriction induced by endothelin- 1 in cannulated vessels, or $0.9 \mathrm{~L}_{100}$. Contractile properties were tested after 1-day activation with endothelin-1, when physical remodeling is not yet present [15]. The results show that activation at low distension induces a change in the contractile properties. Contractile force increased at lower levels of distension, at the expense of force development at higher distension. Such changes were not observed when vessels were activated at $0.9 \mathrm{~L}_{100}$, suggesting that the changes are related to the small diameter associated with normal vasoconstriction. Whether these changes depend on the concentration or duration of activation with endothelin-1 remains to be determined. In addition, further research is needed to elucidate whether these changes relate to remodeling of the contractile apparatus within the cell, or if it is due to cell rearrangement. 
Fig. 7. a Immunostaining of cremaster muscle sections with the mAb directed against the $\beta_{3}$-integrin subunit (F11). Positive staining was observed in the media of the arteriole. No staining was observed in the vein or the surrounding tissue. b Control sections without the primary antibody were negative. The micrographs are typical of results from 2 specimen.

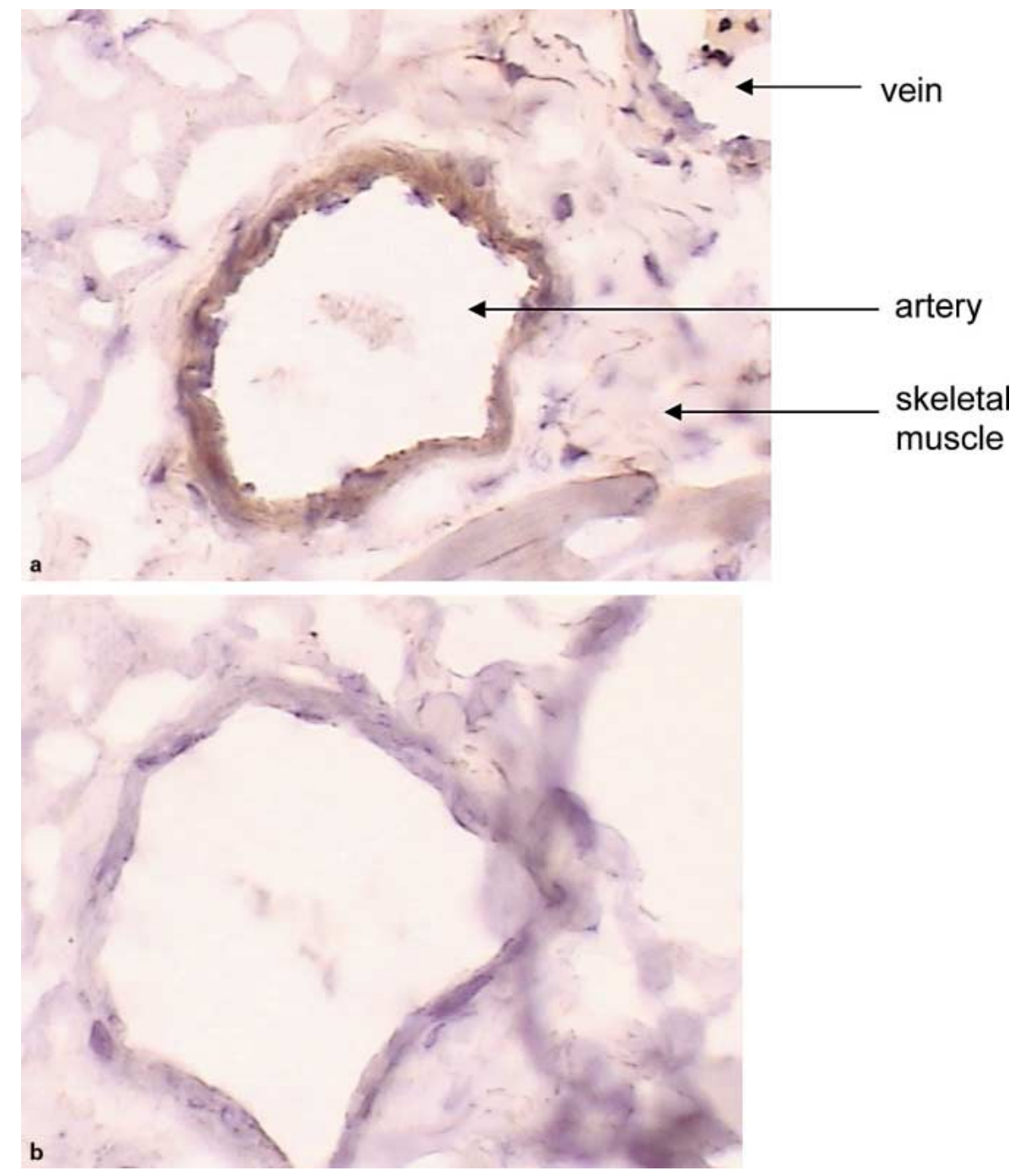

Fig. 8. Effect of antibodies on collagen gel contraction. The $\mathrm{mAb}$ F11, directed against the $\beta_{3}$-integrin subunit $(n=5)$, significantly enhanced contraction. The $\mathrm{mAb} \mathrm{Ha} 2 / 5$, directed against the $\beta_{1}$-integrin subunit ( $\left.n=5\right)$, significantly inhibited contraction, as compared to control $(\mathrm{n}=8) .{ }^{*} \mathrm{p}<0.001$.

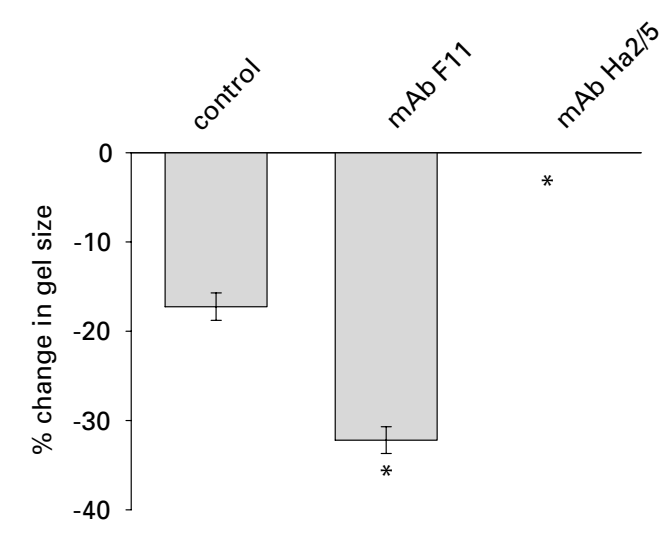




\section{Physical Remodeling}

In the present study we used our previously established model of eutrophic remodeling [15] to investigate the mechanisms involved in activation-induced remodeling. Physical remodeling was observed after 3 days of strong vasoconstriction, induced by endothelin-1. The reduction in diameter is evident at high pressure levels only, resembling the characteristic changes seen in spontaneously hypertensive rats as compared to Wistar-Kyoto rats [21]. Work from our laboratory and that of others suggest that signal transduction pathways induced by vasoconstrictors, pressure, and growth factors converge at the level of ERK1/2. Thus, pressure and angiotensin II act synergistically to activate ERK1/2 in resistance arteries [11]. Pressure may also cross-activate the platelet-derived growth factor receptor and activate ERK1/2 [13]. Therefore, we hypothesized that a key role in the transition of constriction to physical remodeling may be played by ERK1/2. However, the data obtained in the culture experiments show that tyrosine kinases and ERK1/2 are not essential in remodeling, as induced by endothelin-1 in these vessels. In addition, the data with high potassium medium show that a relatively simple means of vasoconstriction is sufficient to induce remodeling. Thus, these results do not provide evidence for a role of signal transduction pathways initiated by ERK1/2 in this model, and alternative mechanisms need to be considered.

One such alternative, but less-defined mechanism of remodeling may involve integrins. Integrins are transmembrane proteins that serve many functions, including adhesion, migration, signal transduction and perhaps also fulfill a mechanosensory role [22]. The $\alpha_{v} \beta_{3}$ integrin is a receptor for vitronectin, fibronectin and osteopontin [23], proteins that may form a provisional matrix during growth and remodeling processes. Expression of the $\alpha_{\mathrm{v}} \beta_{3^{-}}$ integrin is enhanced specifically during low blood flowrelated inward remodeling [24]. Thus, both the $\alpha_{v} \beta_{3}$ integrin and its ligands have been associated with inward remodeling. In addition, the $\alpha_{v} \beta_{3}$-integrin is overexpressed in spontaneously hypertensive rats over WistarKyoto rats, leading others to the suggestion that remodeling may relate to the anchoring function of integrins [25]. The present study now suggests an active role for integrins in remodeling, as the $\beta_{3}$-integrin antibody enhanced remodeling induced by endothelin- 1 . The $\beta_{3}$-integrin subunit was located by immunostaining in the media of the arteriole, in agreement with a smooth muscle-dependent process.

\section{Collagen Contraction}

To study the role of integrins in the relationship between two main players in the remodeling process, smooth muscle cells and collagen fibers, more directly, a collagen contraction assay was used [26]. This assay is used frequently as a model for wound healing and involves the reorganization of collagen fibers by fibroblasts or smooth muscle cells. It has recently also been used to study processes related to vascular remodeling [27]. We speculated that integrin-dependent collagen rearrangement plays a similar role in vascular remodeling. Thus, we hypothesized that the increase in remodeling as induced by the mAb F11 may result from an augmented capacity to rearrange collagen fibers in the vessel wall. The results of the collagen gel experiments substantiate this hypothesis, as collagen compaction was clearly enhanced by the $\beta_{3^{-}}$ integrin subunit antibody. Such enhanced capacity to compact collagen gels in the presence of certain antibodies directed against the $\alpha_{v} \beta_{3}$-integrin or its subunits has been observed by others, using either smooth muscle cells [28] or fibroblasts [29], and involves the increase in $\alpha$-smooth muscle actin expression and its organization into stress fibers [28]. This effect is specifically related to some function-blocking antibodies, and not observed with RGD peptides [28]. This may explain the negative result with the cyclic RGD peptide XJ735 in the present study. Of relevance here may also be the observations that the antibody F11 inhibits smooth muscle migration [30] and proliferation [31]. Whether these effects are indirectly contributing to inward remodeling remains to be determined.

We also observed that the antibody directed against the $\beta_{1}$-integrin collagen inhibited collagen contraction. This finding did not correspond to remodeling events in the cultured arterioles. The reason for this difference may be that the expression pattern of integrins or the accessibility of antibodies to their ligands differs between cultured cells and the intact vessel preparation. It can therefore not be ruled out that besides the $\alpha_{v} \beta_{3}$ integrin, other integrins play a role in remodeling.

\section{Conclusions}

In this study, several approaches were used to elucidate the relevant stimuli and signaling pathways that are involved in the processes of vascular remodeling. The data are consistent with both experimental and clinical evidence, which have also suggested that physical remodeling may occur as a result of persistent functional responses. The results show that conventional growth 
mechanisms (which would be expected to involve tyrosine and mitogen-activated kinases) seem not to be involved in eutrophic remodeling. Rather, the process appears to require the transmission of information from activated smooth muscle cells via integrins to the extracellular matrix. Therefore, the present study reveals a novel mechanism for eutrophic inward remodeling, which involves the reorganization of the extracellular matrix by activated smooth muscle cells through integrins.

\section{Acknowledgments}

The authors wish to thank Mette Schandorf, Helle Zibrantsen, Karen Skjødt, Henriette Johanson and Frode Iversen for technical assistance. This research has been supported by a Marie Curie Fellowship of the European Community, program Quality of Life, under contract No. QLK3-CT-2001-51011. Support was also received from The Netherlands Heart Foundation (NHS 2001.D038), the Danish Medical Research Council and the Danish Heart Foundation.

\section{References}

1 Mulvany MJ, Baumbach GL, Aalkjaer C, Heagerty AM, Korsgaard N, Schiffrin EL, Heistad DD: Vascular remodeling. Hypertension 1996; 28:505-506.

2 Griffin SA, Brown WC, MacPherson F, McGrath JC, Wilson VG, Korsgaard N, Mulvany MJ, Lever AF: Angiotensin II causes vascular hypertrophy in part by a non-pressor mechanism. Hypertension 1991;17:626-635.

$3 \mathrm{Su}$ EJ, Lombardi DM, Siegal J, Schwartz SM: Angiotensin II induces vascular smooth muscle cell replication independent of blood pressure. Hypertension 1998;31:1331-1337.

4 Mulvany MJ, Baandrup U, Gundersen HJ: Evidence for hyperplasia in mesenteric resistance vessels of spontaneously hypertensive rats using a three-dimensional disector. Circ Res 1985;57:794-800.

5 Rizzoni D, Porteri E, Castellano M, Bettoni G, Muiesan ML, Muiesan P, Giulini SM, AgabitiRosei E: Vascular hypertrophy and remodeling in secondary hypertension. Hypertension 1996;28:785-790.

6 Korsgaard N, Aalkjaer C, Heagerty AM, Izzard AS, Mulvany MJ: Histology of subcutaneous small arteries from patients with essential hypertension. Hypertension 1993;22:523-526.

7 Heagerty AM, Aalkjaer C, Bund SJ, Korsgaard N, Mulvany MJ: Small artery structure in hypertension. Dual processes of remodeling and growth. Hypertension 1993;21:391-397.

8 Schiffrin EL, Deng LY, Larochelle P: Morphology of resistance arteries and comparison of effects of vasoconstrictors in mild essential hypertensive patients. Clin Invest Med 1993;16: 177-186.

9 Rizzoni D, Porteri E, Castellano M, Bettoni G, Muiesan ML, Tiberio G, Giulini SM, Rossi G, Bernini G, Agabiti-Rosei E: Endothelial dysfunction in hypertension is independent from the etiology and from vascular structure. Hypertension 1998;31:335-341.

10 Falloon BJ, Heagerty AM: In vitro perfusion studies of human resistance artery function in essential hypertension. Hypertension 1994;24: 16-23.

11 Matrougui K, Eskildsen-Helmond YEG, Fiebeler A, Henrion D, Levy BI, Tedgui A, Mulvany MJ: Angiotensin II stimulates extracellular signal-regulated kinase activity in intact pres- surized rat mesenteric resistance arteries. Hypertension 2000;36:617-621.

12 Wesselman JP, Dobrian AD, Schriver SD, Prewitt RL: Src tyrosine kinases and extracellular signal-regulated kinase $1 / 2$ mitogen-activated protein kinases mediate pressure-induced c-fos expression in cannulated rat mesenteric small arteries. Hypertension 2001;37:955-960.

13 Eskildsen-Helmond YE, Mulvany MJ: Pressure-induced activation of extracellular signalregulated kinase $1 / 2$ in small arteries. Hypertension 2003;41:891-897.

14 Bakker ENTP, van der Meulen ET, Spaan JAE, VanBavel E: Organoid culture of cannulated rat resistance arteries: Effect of serum factors on vasoactivity and remodeling. Am J Physiol 2000;278:H1233-H1240.

15 Bakker EN, van der Meulen ET, van den Berg BM, Everts V, Spaan JA, VanBavel E: Inward remodeling follows chronic vasoconstriction in isolated resistance arteries. J Vasc Res 2002;39: 12-20.

16 Mulvany MJ, Halpern W: Contractile properties of small arterial resistance vessels in spontaneously hypertensive and normotensive rats. Circ Res 1977;41:19-26.

17 Spurrell BE, Murphy TV, Hill MA: Tyrosine phosphorylation modulates arteriolar tone but is not fundamental to myogenic response. Am J Physiol 2000;278:H373-H382.

18 Langille BL, Bendeck MP, Keeley FW: Adaptations of carotid arteries of young and mature rabbits to reduced carotid blood flow. Am J Physiol 1989;256:H931-H939.

19 Buus CL, Pourageaud F, Fazzi GE, Janssen G, Mulvany MJ, De Mey JGR: Smooth muscle cell changes during flow-related remodeling of rat mesenteric resistance arteries. Circ Res 2001;89:180-186.

20 Christensen KL, Mulvany MJ: Vasodilatation, not hypotension, improves resistance vessel design during treatment of essential hypertension: A literature survey. J Hypertens 2001;19: 1001-1006.

21 Intengan HD, Thibault G, Li JS, Schiffrin EL: Resistance artery mechanics, structure, and extracellular components in spontaneously hypertensive rats: Effects of angiotensin receptor antagonism and converting enzyme inhibition. Circulation 1999;100:2267-2275.
22 Davis MJ, Wu X, Nurkiewicz TR, Kawasaki J, Davis GE, Hill MA, Meininger GA: Integrins and mechanotransduction of the vascular myogenic response. Am J Physiol 2001;280:H1427H1433.

23 Byzova TV, Rabbani R, D'Souza SE, Plow EF: Role of integrin alpha(v)beta3 in vascular biology. Thromb Haemost 1998;80:726-734.

24 Ward MR, Tsao PS, Agrotis A, Dilley RJ, Jennings GL, Bobik A: Low blood flow after angioplasty augments mechanisms of restenosis: Inward vessel remodeling, cell migration, and activity of genes regulating migration. Arterioscler Thromb Vasc Biol 2001;21:208-213.

25 Intengan HD, Schiffrin EL: Structure and mechanical properties of resistance arteries in hypertension: Role of adhesion molecules and extracellular matrix determinants. Hypertension 2000;36:312-318.

26 Guidry C, Grinnell F: Studies on the mechanism of hydrated collagen gel reorganization by human skin fibroblasts. J Cell Sci 1985;79:6781.

27 Li S, Moon JJ, Miao H, Jin G, Chen BP, Yuan S, Hu Y, Usami S, Chien S: Signal transduction in matrix contraction and the migration of vascular smooth muscle cells in three-dimensional matrix. J Vasc Res 2003;40:378-388.

28 Scaffidi AK, Moodley YP, Weichselbaum M, Thompson PJ, Knight DA: Regulation of human lung fibroblast phenotype and function by vitronectin and vitronectin integrins. J Cell Sci 2001;114:3507-3516.

29 Blindt R, Krott N, Hanrath P, vom Dahl J, van EG, Bosserhoff AK: Expression patterns of integrins on quiescent and invasive smooth muscle cells and impact on cell locomotion. J Mol Cell Cardiol 2002;34:1633-1644.

30 Bendeck MP, Irvin C, Reidy M, Smith L, Mulholland D, Horton M, Giachelli CM: Smooth muscle cell matrix metalloproteinase production is stimulated via alpha(v)beta(3) integrin. Arterioscler Thromb Vasc Biol 2000;20:1467_ 1472.

31 Sajid M, Zhao R, Pathak AS, Smyth SS, Stouffer GA: $\alpha v \beta 3$ Integrin antagonists inhibit thrombin-induced proliferation and focal adhesion formation in smooth muscle cells. Am J Physiol 2003;85:C1330-C1338. 